\title{
Quantitative phosphoproteomics reveals genistein as a modulator of cell cycle and DNA damage response pathways in triple-negative breast cancer cells
}

\author{
YI FANG $^{1 *}$, QIAN ZHANG $^{4 *}$, XIN WANG $^{1}$, XUE YANG $^{1}$, XIANGYU WANG $^{1}$, \\ ZHEN HUANG $^{2}$, YUCHEN JIAO ${ }^{3}$ and JING WANG ${ }^{1}$ \\ Departments of ${ }^{1}$ Breast Surgical Oncology and ${ }^{2}$ Abdominal Surgical Oncology, ${ }^{3}$ Laboratory of Cell and \\ Molecular Biology and State Key Laboratory of Molecular Oncology, Cancer Institute and Hospital, Chinese Academy \\ of Medical Sciences and Peking Union Medical College, Beijing; ${ }^{4}$ Department of Gastroenterology, \\ Beijing Tiantan Hospital, Capital Medical University, Beijing, P.R. China
}

Received September 8, 2015; Accepted December 15, 2015

DOI: $10.3892 /$ ijo.2016.3327

\begin{abstract}
Around one sixth of breast cancer cases are classified as triple-negative breast cancer (TNBC), named after the absence of the expression of estrogen receptor (ER), progesterone receptor (PR), and human epidermal growth factor receptor 2 (HER2); however, patients with TNBC suffer from poor clinical outcome and shortage of targeted therapy. Genistein, an estrogenic soy isoflavone, shows anticancer effects in TNBC cells such as inducing G2/M cell cycle arrest and apoptosis. However, the underlying mechanism of its anticancer effects is poorly understood and its elucidation can help the development of novel therapeutic strategies for TNBC. In this study, by combining isobaric tag-based TMT labeling with titanium dioxide-based phosphopeptide enrichment, we quantitated 5,445 phosphorylation sites on 2,008 phosphoproteins in the TNBC cell line MDA-MB-231, upon genistein treatment. Our analysis revealed 332 genisteinregulated phosphorylation sites on 226 proteins. Our data show that genistein can regulate several biological processes during the cell cycle, including DNA replication, cohesin
\end{abstract}

Correspondence to: Dr Jing Wang, Cancer Institute and Hospital, Chinese Academy of Medical Sciences and Peking Union Medical College, Chaoyangqu, Panjiayuan, Nanli 17, Beijing, P.R. China E-mail: wangjing@cicams.ac.cn

${ }^{*}$ Contributed equally

Abbreviations: TMT, tandem mass tag; TNBC, triple-negative breast cancer; ATR, ataxia telangiectasia and Rad3-related protein; ER, estrogen receptor; PR, progesterone receptor; HER2, human epidermal growth factor receptor 2; ORC, origin recognition complex; MCM, mini chromosome maintenance

Key words: genistein, tandem mass tag, quantitative phosphoproteomics, triple-negative breast cancer, cell cycle, DNA damage response, BRCA1, CDK1, ataxia telangiectasia complex cleavage, and kinetochore formation. Furthermore, genistein can also activate DNA damage response, including activation of ATR and BRCA1 complex. Overall, our study presents evidence at a phosphoproteomic level that genistein is able to inhibit TNBC cell growth by regulating the cell cycle and DNA damage response in a more complex manner. Our findings help elucidate the mechanisms through which genistein exerts its anticancer effects in TNBC cells.

\section{Introduction}

Breast cancer is the most common cancer and the leading cause of cancer-related death in women worldwide (1). It is not considered to be only one disease but a heterogeneous group of different diseases of distinct molecular subtypes. Breast cancer can be categorized into four subtypes, luminal A, luminal B, basal-like and HER2-positive $(2,3)$. Three biomarkers, estrogen receptor (ER), progesterone receptor (PR), and human epidermal growth factor receptor 2 (HER2) are often used for subtyping of breast cancer pathologically (2). Although the overall mortality rate for breast cancer patients has declined in developed countries, the patients diagnosed of basal-like subtype have a poorer short-term prognosis than those diagnosed with other breast cancer subtypes. The majority of basal-like breast cancer cases are also referred to as 'triplenegative' because they are characterized as the lack of the expression of these three biomarkers. Currently, no targeted therapies are available for these tumors. Thus, there is great unmet medical need for the development of novel molecular targeted therapeutic strategies.

Soy products have long been suggested to be useful in the prevention of cancer development $(4,5)$. Epidemiological studies have shown the chemopreventive effect of soy intake for breast cancer $(4,6)$. Especially, studies have shown that Asian women, who consume a diet high in soy products, have a lesser incidence of breast cancer and risk of breast cancer recurrence than the women in western counties (6).

Genistein, a phytoestrogen, is the major isoflavonoid contained in soybeans and is considered the active micronutrient 
responsible for the chemopreventive effect of soy. It has a broad spectrum of anticancer properties in triple negative breast cancer (TNBC) cells. Genistein can inhibit cell growth (7), induce apoptosis (8) and G2/M phase arrest (9), and decrease cell invasiveness (10) in TNBC cells. Although a number of studies have been performed to dissect the molecular mechanisms of the effects of genistein on TNBC cells (8-13), they cannot comprehend its pleiotropic effects because of the limited throughput of traditional biochemical methods.

Multiplexed quantitation via isobaric labeling reagents [e.g., tandem mass tags (TMT) (14) and isobaric tags for relative and absolute quantitation (iTRAQ) (15)] combined with phosphopeptide enrichment has been employed to dissect complex signaling pathways using mass spectrometry. Nirujogi et al combined an 8-plex TMT labeling strategy with titanium dioxide-based phosphopeptide enrichment to examine the changes of the phosphoproteome in the brains of rats after the exposure to VX, a nerve agent (16). Roitinger and colleagues combined a 4-plex iTRAQ labeling strategy with a phosphopeptide enrichment pipeline (immobilized metal affinity chromatography coupled with metal oxide affinity chromatography) to characterize the DNA damage response signaling pathway in Arabidopsis thaliana (17). Herein, we employed a TMT-based quantitative phosphoproteomic approach to identify genistein-regulated changes of phosphorylation in TNBC cell line, MDA-MB-231 after the short-term treatment. All together, we identified 5,445 phosphorylation sites on 2,008 phosphoproteins out of 3,452 proteins identified. The TMT-based quantitation revealed 332 genistein-regulated phosphorylation events. Bioinformatics analysis revealed that genistein can modulate phosphorylation on proteins involved in regulation of the cell cycle and DNA damage response. They include critical components of DNA replication fork, cohesin complex, kinetochores, and the BRCA1 complex. Manual literature curation provides evidence that genisteininduced changes on these proteins could contribute to its anticancer effects. Overall, our data set provides a valuable resource for further investigation on the anticancer molecular mechanism of genistein in TNBC cells.

\section{Materials and methods}

Cell line and reagents. The breast cancer cell line MDA-MB231 was maintained in DMEM supplemented with FBS, L-glutamine, penicillin, streptomycin at $37^{\circ} \mathrm{C}$ in $5 \% \mathrm{CO}_{2}$. Genistein was purchased from Sigma-Aldrich (St. Louis, MO, USA). Titanspheres ( $\mathrm{TiO}_{2}, 5 \mu \mathrm{m}$ beads) were from GL Sciences Inc. (Torrance, CA, USA). L-1-Tosylamide-2-phenylethyl chloromethyl ketone (TPCK) treated trypsin was from Worthington Biochemical Corp. (Lakewood, NJ, USA). All other reagents used in this study were from Fisher Scientific (Pittsburgh, PA, USA).

Cell lysis, protein digestion and TMT labeling. MDA-MB-231 cells were plated at $3 \times 10^{6}$ cells per $150-\mathrm{mm}$ plate overnight. Three populations of cells were subjected to different treatments with $40 \mu \mathrm{M}$ genistein for 0,3 or $24 \mathrm{~h}$, respectively. The treatments were carried out in biological duplicates. After treatment, cells were washed with PBS, collected and lysed in lysis buffer (4\% SDS, $50 \mathrm{mM}$ triethylammonium bicarbonate (TEABC), $10 \mathrm{mM}$ sodium fluoride, $1 \mathrm{mM}$ sodium orthovanadate and $1 \mathrm{mM} \beta$-glycerophosphate, $2.5 \mathrm{mM}$ sodium pyrophosphate) by sonication. After centrifugation at $16,000 \mathrm{x} \mathrm{g}$ at $15^{\circ} \mathrm{C}$ for $20 \mathrm{~min}$, the supernatant was collected and the protein concentration was determined using bicinchoninic acid (BCA) assay (Pierce, Waltham, MA, USA). An equal amount of protein $(400 \mu \mathrm{g})$ from each condition was reduced by DTT at a final concentration of $5 \mathrm{mM}$ at $60^{\circ} \mathrm{C}$ for $20 \mathrm{~min}$ and alkylated using $10 \mathrm{mM}$ iodoacetamide for $10 \mathrm{~min}$ at room temperature (RT) in the dark.

The samples were then subjected to the filter-assisted sample preparation protocol (18) with minor modifications. Briefly, after reduction and alkylation, the protein was mixed with UA solution (8 M urea in $50 \mathrm{mM}$ TEABC, $\mathrm{pH} 8.0$ ) to dilute the concentration of SDS to $0.1 \%$ and transferred to an Amicon Ultra centrifugal filter unit (30 kDa cut-off, Millipore). The unit was centrifuged at $14,000 \mathrm{x}$ g at $20^{\circ} \mathrm{C}$ for $15 \mathrm{~min}$. The concentrate was diluted with $400 \mu \mathrm{l}$ of UA solution and then subjected to centrifugation. This step was repeated once. The resulting concentrate was then diluted with $400 \mu 1$ of $50 \mathrm{mM}$ TEABC, $\mathrm{pH} 8.0$ followed by centrifugation. This step was repeated once. The concentrate was transferred to a fresh tube and subjected to tryptic digestion overnight. The resulting peptides were dried completely in a vacuum concentrator and kept at $-80^{\circ} \mathrm{C}$.

Tandem mass tag (TMT) labeling was carried out according to the manufacturer instructions. Briefly, tryptic peptides from each sample was reconstituted in $100 \mu \mathrm{l}$ of $50 \mathrm{mM}$ TEABC buffer and mixed with the TMT reagent reconstituted in $41 \mu \mathrm{l}$ of anhydrous acetonitrile (ACN), incubated at RT for $1 \mathrm{~h}$. All the labeled peptides from each sample were equally mixed, dried completely in a vacuum concentrator and kept at $-80^{\circ} \mathrm{C}$.

Fractionation of peptides by basic reversed-phase liquid chromatography (bRPLC). TMT-labeled peptide mixture were resuspended in $1 \mathrm{ml}$ of $10 \mathrm{mM}$ TEABC, $\mathrm{pH} 8.0$ and loaded on a XBridge BEH C18 column, 130Å, $5 \mu \mathrm{m}, 4.6$ mm X $250 \mathrm{~mm}$ (Waters, Milford, MA, USA), and fractionated on an Agilent 1100 Series HPLC system by basic reversed-phase chromatography at a flow rate of $400 \mu \mathrm{l} / \mathrm{min}$. Mobile phase consisted of $10 \mathrm{mM}$ TEABC, pH 8.0 (buffer A) and $10 \mathrm{mM}$ TEABC, $90 \%$ acetonitrile, $\mathrm{pH} 8.0$ (buffer $\mathrm{B}$ ). After loading $1 \mathrm{ml}$ of sample (2.4 mg of protein) onto the column, the peptides were separated using the following gradient: $2 \mathrm{~min}$ isocratic hold at $0 \% \mathrm{~B}, 0$ to $15 \%$ solvent $\mathrm{B}$ in $8 \mathrm{~min} ; 15$ to $28.5 \%$ solvent $\mathrm{B}$ in $33 \mathrm{~min} ; 28.5$ to $34 \%$ solvent B in $5.5 \mathrm{~min} ; 34$ to $60 \%$ solvent B in $13 \mathrm{~min}$, for a total gradient time of $64.5 \mathrm{~min}$. Using $96 \mathrm{X}$ $1 \mathrm{ml}$ well plates (Fisher, \#7701-5200), fractions were collected every $0.6 \mathrm{~min}$ for a total of 96 fractions through the elution profile of the separation. Collection (5\%) from each well were merged into 6 fractions and dried by vacuum centrifugation for the LC-MS/MS analysis of the proteomic changes in cells. The rest collected from each well was merged into 12 fractions and dried by vacuum centrifugation for $\mathrm{TiO}_{2}$-based phosphopeptide enrichment.

Phosphopeptide enrichment strategy. The 12 fractions of TMT-labeled peptides were subjected to $\mathrm{TiO}_{2}$-based phosphopeptide enrichment as described by Larsen et al (19) with minor modification. Briefly, $\mathrm{TiO}_{2}$ beads were pretreated by 
incubation with 2,5-dihydroxybenzoic acid (DHB) solution ( $80 \% \mathrm{v} / \mathrm{v}$ ACN, $3 \% \mathrm{v} / \mathrm{v}$ TFA, $5 \% \mathrm{w} / \mathrm{v}$ DHB) for $20 \mathrm{~min}$ at room temperature. Each fraction was resuspended in DHB solution and incubated with pretreated $\mathrm{TiO}_{2}$ beads (Peptides: $\mathrm{TiO}_{2}=1: 1$ ). Phosphopeptide-bound $\mathrm{TiO}_{2}$ beads were washed twice with $400 \mu 1$ of washing solution ( $80 \% \mathrm{v} / \mathrm{v}$ ACN, $3 \% \mathrm{v} / \mathrm{v}$ TFA). Peptides were eluted three times with $20 \mu \mathrm{l}$ of $4 \% \mathrm{v} / \mathrm{v}$ ammonia into $20 \mu \mathrm{l}$ of $20 \% \mathrm{v} / \mathrm{v}$ TFA and dried completely by vacuum centrifugation. The dried peptides were resuspended in $50 \mu \mathrm{l}$ 0.15\% TFA, and desalted using C18 Stage Tips (20).

Liquid chromatography tandem mass spectrometry. LC-MS/ MS analysis of peptides and phosphopeptides was carried out using a reversed phase liquid chromatography system interfaced with an LTQ-Orbitrap Velos mass spectrometer. The mass spectrometer was operated in the 'high-high' mode, where mass spectra of both precursor and product ions were acquired in the high resolution Orbitrap analyzer (Thermo Scientific). The peptides were loaded onto an analytical column ( $10 \mathrm{~cm}$ x $75 \mu \mathrm{m}$, Magic C18 AQ $5 \mu \mathrm{m}, 120 \AA$ Å) by $0.1 \%$ $\mathrm{v} / \mathrm{v}$ formic acid and eluted using an ACN gradient $(0-60 \% \mathrm{v} / \mathrm{v})$ containing $0.1 \% \mathrm{v} / \mathrm{v}$ formic acid. The settings were: i) Precursor scans (FTMS) from 350-1,800 m/z at 30,000 resolution; and ii) MS2 scan (FTMS) of HCD fragmentation of the 10 most intense ions (isolation width: $1.20 \mathrm{~m} / \mathrm{z}$; normalized collision energy: 40.0 ; activation time $=0.1 \mathrm{msec}$; FT first mass value: 110.00 (fixed)) at 15,000 resolution.

Mass spectrometry data analysis. The tandem mass spectra were searched using Andromeda algorithm (21) against a human UniProt database (released in February, 2014) through the MaxQuant platform (version 1.4.1.2) $(22,23)$. The search parameters included: 6plex TMT; a maximum of two missed cleavages; fixed modification: carbamidomethylation of cysteine; variable modification: protein $\mathrm{N}$-term acetylation, oxidation of methionine, and phosphorylation of serine, threonine and tyrosine. The first search and main search for peptide tolerance were set to $20 \mathrm{ppm}$ and $4.5 \mathrm{ppm}$, respectively. The FTMS MS/MS tolerance was set to $50 \mathrm{ppm}$. The maximum number of modifications per peptide was set to 5 and the maximum charge was set at 7 . The reward type of the target-decoy analysis was chosen. The peptide-spectrum match (PSM) false discovery rate (FDR), protein FDR and the site decoy fraction were set to 0.01 . The minimum peptide length was set to 7 . The minimal scores for unmodified and modified peptides were 0 and 40, respectively. The minimal delta score for unmodified and modified peptides were 0 and 17, respectively. The minimum of unique and razor peptides for identification was set to 1 . The reporter ion intensities for each PSM with PIF (precursor ion fraction) $>0.75$ were calculated using MaxQuant. The quantitation of identified proteins was determined by normalized reporter ion intensities using at least 1 razor/unique non-phosphopeptide. The quantitation of each identified phosphosites were determined by normalized reporter ion intensities using the least modified peptide and normalized. The probability of phosphorylation for each Ser/Thr/Tyr site on each peptide was calculated using Andromeda (MaxQuant). The mass spectrometry proteomics data and the supplementary data have been deposited to the ProteomeXchange Consortium (24) via the PRIDE partner

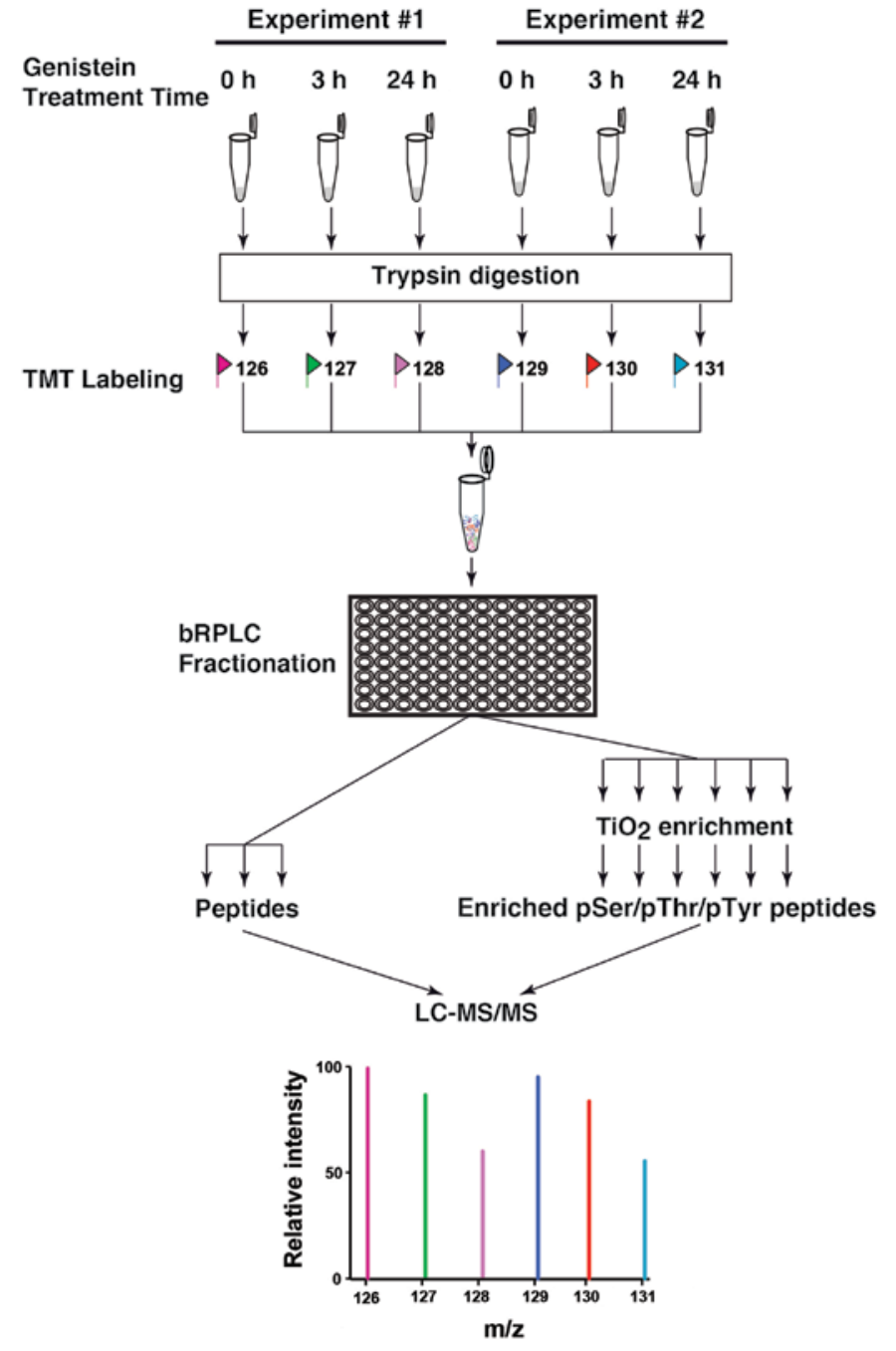

Figure 1. A schematic illustration of the TMT-based quantitative whole proteomic/phosphoproteomic pipeline. Cells treated with genistein for different time were subjected to FASP-based sample preparation. 6-plex TMT labeling and bRPLC fractionation were carried out and the collected fractions were concatenated. A portion of these fractions were subjected to $\mathrm{TiO}_{2}$ enrichment. Enriched phosphopeptides along with unprocessed peptides were analyzed at an Orbitrap-equipped mass spectrometer.

repository with the dataset identifier PXD002735 (http://www. ebi.ac.uk/pride/archive/projects/PXD002735/files).

Bioinformatics analysis. Molecular function and cellular localization of phosphoproteins were obtained from the PANTHER Classification System $(25,26)$. Enrichment analysis of biological process GO term of phosphoproteins was performed using the DAVID functional annotation tool $(27,28)$.

\section{Results}

Mass spectrometric analysis of genistein-treated TNBC cells. Previously, several studies have shown that genistein inhibits cell growth and induces apoptosis in a dose-dependent manner $(8,11,12,29)$ during the treatment time ranging from $24 \mathrm{~h}$ to 6 days. However, the short-term effects of genistein on the signaling network in TNBC MDA-MB-231 cells during the first 24-h treatment, especially at 3-h time point, have not been investigated. By combining a 6-plex TMT labeling 
A

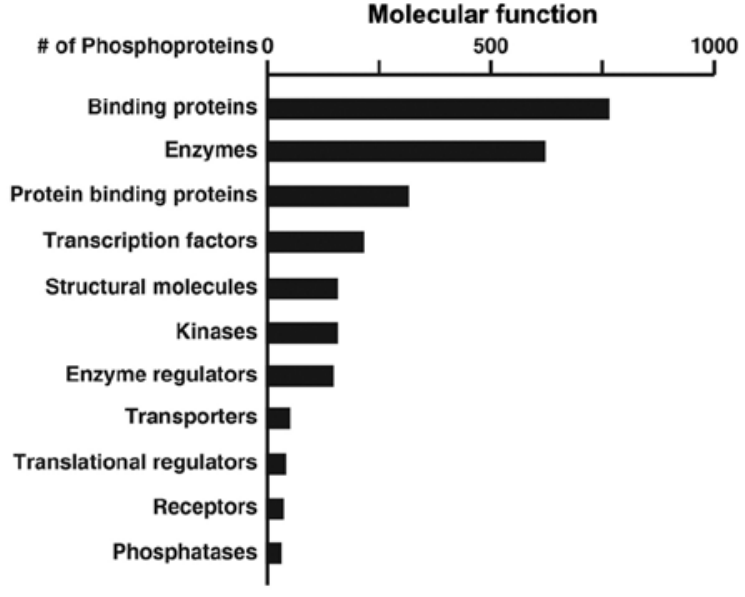

B

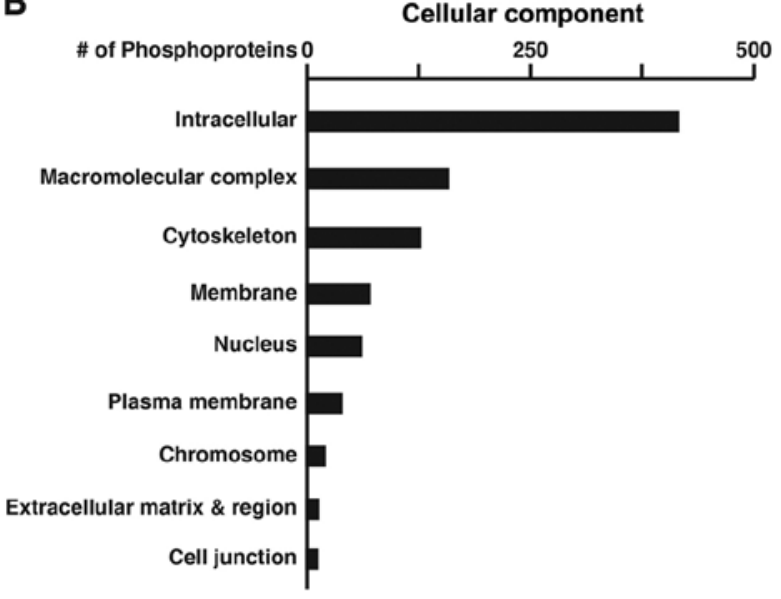

Figure 2. Molecular function and cellular localization distribution of phosphoproteins identified in our study. The GO annotation describing the numbers of identified phosphoproteins with different molecular functions (A) and cellular locations (B) as obtained from the PANTHER.

A

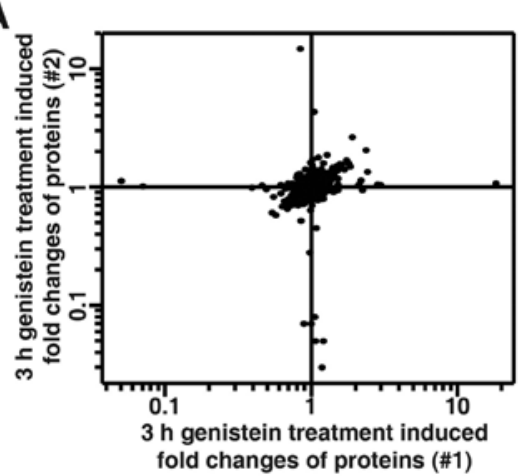

\section{C}

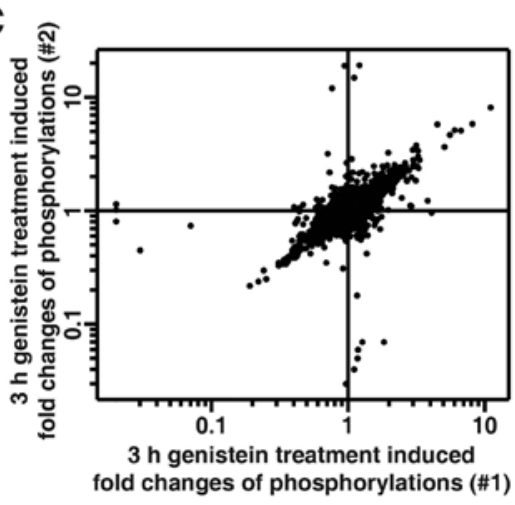

B

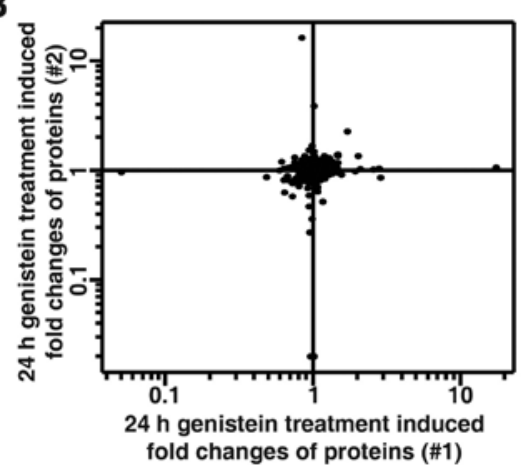

D

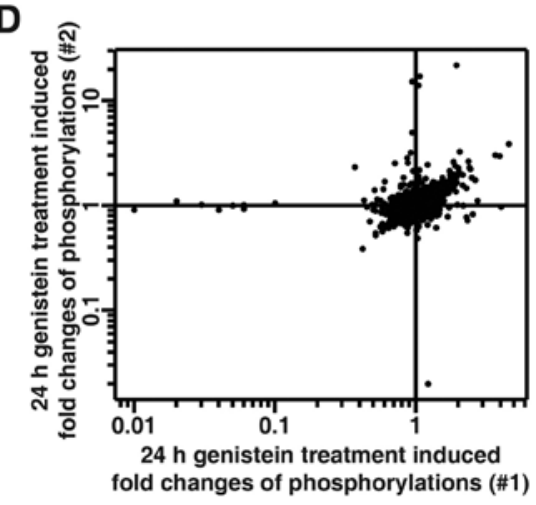

Figure 3. Quantitative analysis of fold changes of proteins and phosphorylation in genistein-treated MDA-MB-231 cells. Density scatter plot of fold changes of the protein level (A and B) and phosphorylation level $(\mathrm{C}$ and $\mathrm{D})$ in $3 \mathrm{~h}(\mathrm{~A}$ and $\mathrm{C})$ and $24 \mathrm{~h}(\mathrm{~B}$ and $\mathrm{D})$ genistein-treated MDA-MB-231 cells from biological duplicates. All the data are $\log 10$-transformed.

strategy and a $\mathrm{TiO}_{2}$-based phosphopeptide enrichment strategy coupling with high resolution Fourier transform mass spectrometry, we systematically measure the changes of the cellular phosphoproteome in biological duplicate experiments at two different time points, 3-h and 24-h treatments, as shown in Fig. 1.

Eighteen LC-MS/MS runs generated a total of 247,126 mass spectra. The mass spectra were searched against a Uniprot database (released in February, 2014) using Andromeda (21) through MaxQuant (Version 1.4.1.2) (23). Using a FDR cut-off of $1 \%$ at both peptide and protein levels, a target-decoy analysis generated 27,666 peptide-spectrum-matches, of which 14,462 were phosphopeptide-spectrum-matches. After excluding reverse and contaminating matches, we identified a total of 3,452 proteins and 12,813 peptides. Among these identified peptides, 4,562 were phosphopeptides that contained 5,445 phosphorylation sites (4,698 phosphoserine, 725 phosphothreonine, 22 phosphotyrosine sites). These phosphopeptides were mapped to 2,008 phosphoproteins. Fig. 2 shows the numbers of these phosphoproteins categorized by molecular function (A) or cellular component (B) based on the annotation by the PANTHER classification system. 
Table I. Statistical analysis of quantitative proteomics and phosphoproteomics data.

A, Fold change of the protein level of in MDA-MB-231 cells after treatment with genistein

\begin{tabular}{lccccc}
\hline Experiment & $\begin{array}{c}\text { Time point } \\
\text { (h) }\end{array}$ & Median & $\begin{array}{c}\text { Mean } \\
(\log 10 \text { transformed) }\end{array}$ & $\begin{array}{c}\text { Standard deviation } \\
(\log 10 \text { transformed) }\end{array}$ & $\begin{array}{c}95 \% \text { Confidence } \\
\text { interval }\end{array}$ \\
\hline$\# 1$ & 3 & 1.03 & 0.00889 & 0.0752 & $0.858-1.213$ \\
& 24 & 1.01 & 0.00504 & 0.0604 & $0.880-1.162$ \\
$\# 2$ & 3 & 1.02 & 0.00182 & 0.0951 & $0.807-1.250$ \\
& 24 & 1.02 & 0.00475 & 0.0732 & $0.854-1.196$ \\
\hline
\end{tabular}

$\mathrm{B}$, Fold change of the phosphorylation level in MDA-MB-231 cells after treatment with genistein

\begin{tabular}{lccccc}
\hline Experiment & $\begin{array}{c}\text { Time point } \\
\text { (h) }\end{array}$ & Median & $\begin{array}{c}\text { Mean } \\
(\log 10 \text { transformed) }\end{array}$ & $\begin{array}{c}\text { Standard deviation } \\
(\log 10 \text { transformed) }\end{array}$ & $\begin{array}{c}95 \% \text { Confidence } \\
\text { interval }\end{array}$ \\
\hline$\# 1$ & 3 & 0.99 & 0.00011 & 0.1301 & $0.741-1.350$ \\
& 24 & 0.98 & -0.00636 & 0.0941 & $0.793-1.224$ \\
$\# 2$ & 3 & 0.99 & -0.00048 & 0.1270 & $0.746-1.338$ \\
& 24 & 0.98 & -0.00332 & 0.0889 & $0.809-1.218$ \\
\hline
\end{tabular}

Table II. The genistein-regulated proteins in MDA-MB-231 cells.

\begin{tabular}{|c|c|c|c|c|}
\hline \multirow[b]{2}{*}{ Gene symbol } & \multirow[b]{2}{*}{ Protein } & \multirow[b]{2}{*}{ Accession no. } & \multicolumn{2}{|c|}{ Fold change } \\
\hline & & & $3 \mathrm{~h}$ & $24 \mathrm{~h}$ \\
\hline$C C N B 1$ & G2/mitotic-specific cyclin-B1 & Q9NRN7 & 2.2 & 1.1 \\
\hline$C S T B$ & Cystatin-B & P04080 & 2.6 & 2.0 \\
\hline$E E F 1 B 2$ & Elongation factor $1-\beta$ & P24534 & 1.7 & 1.1 \\
\hline PRC1 & Protein regulator of cytokinesis 1 & O43663 & 1.6 & 1.0 \\
\hline$T K 1$ & Thymidine kinase, cytosolic & P04183 & 1.7 & 1.1 \\
\hline$T P X 2$ & Targeting protein for Xklp2 & Q9ULW0 & 1.6 & 1.1 \\
\hline HISTIHIC & Histone H1.2 & P16403 & 0.57 & 0.87 \\
\hline$T N K S 1 B P 1$ & $182 \mathrm{kDa}$ tankyrase-1-binding protein & Q9C0C2 & 0.57 & 0.63 \\
\hline
\end{tabular}

The quantitation of proteins and phosphosites was determined by the reporter ion intensities using the MaxQuant platform. The reporter ion intensities derived from mass spectra with precursor ion fraction (PIF) of $>0.75$ were considered for the quantitation. The changes of identified proteins were carried out using the quantitation of non-phosphopeptides, while changes in phosphosites were calculated using the least-modified phosphopeptides and then normalized to the changes of the corresponding protein, if possible. We were able to quantitate 2,087 proteins and 4,750 phosphosites (Fig. 3 and data not shown). Table I summarizes the statistics of the quantitative data on the fold-changes of proteins and phosphorylation in genistein-treated MDA-MB-231 cells. The narrow range of $95 \%$ confidence interval suggests that the majority of quantitated proteins remained unchanged during the course of genistein treatment in cells. Previously, TMT-based quantitative proteomics studies have chosen
1.5 -fold change as a cut-off for significant changes $(16,30)$. Thus, we also chose 1.5-fold cut-off for increased protein/ phosphorylation level and a 0.67 -fold cut-off for decreased protein/phosphorylation level. Only the changes of phosphorylation that showed consistency in both biological replicate experiments were considered for further analysis. By using this cut-off, 2,078 out of 2,087 proteins remained unchanged during the $24 \mathrm{~h}$ treatment of TNBC cells with genistein, while the expression level of only 8 proteins were modulated by genistein (Table II). We also identified 332 genistein-regulated phosphorylation sites in our analysis (Table III and data not shown). Fig. 4 shows the distribution of phosphor-serine, -threonine and -tyrosine sites among identified phosphosites (A) and genistein-regulated phosphosites (B).

Genistein regulates a number of biological processes during the cell cycle in TNBC cells. To identify the biological 
Table III. A partial list of genistein-regulated phosphoproteins involved in regulation of the cell cycle in MDA-MB-231 cells.

\begin{tabular}{|c|c|c|c|c|c|c|}
\hline \multirow[b]{2}{*}{ Gene symbol } & \multirow[b]{2}{*}{ Protein } & \multirow[b]{2}{*}{ Uniprot ID } & \multirow[b]{2}{*}{ Phosphosite } & \multirow[b]{2}{*}{ Identified peptides } & \multicolumn{2}{|c|}{ Fold change } \\
\hline & & & & & $3 \mathrm{~h}$ & $24 \mathrm{~h}$ \\
\hline$A K A P 12$ & A-kinase anchor protein 12 & Q02952 & S612 & EGVTPWApSFK & 0.61 & 0.91 \\
\hline AKAP9 & A-kinase anchor protein 9 & Q99996 & S45 & AQSDGQSPpSKK & 1.70 & 0.98 \\
\hline$A N L N$ & Actin-binding protein anillin & Q9NQW6 & S72 & RCpSDNTEVEVSNLENK & 0.56 & 0.91 \\
\hline ARHGAP19 & Rho GTPase-activating protein 19 & Q14CB8 & S422 & pSFSGLIK & 1.72 & 1.05 \\
\hline$B R C A 1$ & $\begin{array}{l}\text { Breast cancer type } 1 \text { susceptibility } \\
\text { protein }\end{array}$ & P38398 & $\begin{array}{l}\text { S753 } \\
\text { S1524 }\end{array}$ & $\begin{array}{l}\text { DLMLpSGER } \\
\text { NYPpSQEELIK }\end{array}$ & $\begin{array}{l}1.99 \\
2.16\end{array}$ & $\begin{array}{l}1.24 \\
1.48\end{array}$ \\
\hline C6orf106 & Uncharacterized protein C6orf106 & Q9H6K1 & S215 & KVEGNFNPFApSPQK & 1.86 & 1.09 \\
\hline $\begin{array}{l}\text { CCNY; } \\
\text { CCNYL1 }\end{array}$ & $\begin{array}{l}\text { Cyclin-Y-like protein } 1 ; \\
\text { Cyclin-Y }\end{array}$ & $\begin{array}{l}\text { Q8ND76; } \\
\text { Q8N7R7 }\end{array}$ & S73; S95 & ASTIFLSKpSQTDVR & 1.56 & 1.20 \\
\hline$C D C 20$ & $\begin{array}{l}\text { Cell division cycle protein } 20 \\
\text { homolog }\end{array}$ & Q12834 & $\begin{array}{l}\text { T106 } \\
\text { T70 }\end{array}$ & $\begin{array}{l}\text { ENQPENSQpTPTKK } \\
\text { VQTpTPSKPGGDR }\end{array}$ & $\begin{array}{l}2.12 \\
2.27\end{array}$ & $\begin{array}{l}1.14 \\
1.19\end{array}$ \\
\hline CDC6 & Cell division control protein 6 homolog & Q99741 & S54 & ALPLpSPR & 1.72 & 1.19 \\
\hline CDCA3 & Cell division cycle-associated protein 3 & Q99618 & S94 & QLpSEVFETEDSK & 1.88 & 0.86 \\
\hline$C D K 1$ & Cyclin-dependent kinase 1; & P06493; & T14; T14; T14 & IGEGpTpYGVVYK & 2.83 & 1.21 \\
\hline$C D K 2$ & Cyclin-dependent kinase 2; & P24941; & Y15; Y15; Y15 & IGEGpTpYGVVYK & 2.29 & 1.12 \\
\hline$C D K 3$ & Cyclin-dependent kinase 3 & Q00526 & Y19; Y19; Y19 & IGEGpTYGVVpYK & 2.44 & 1.16 \\
\hline CDK12 & Cyclin-dependent kinase 12 & Q9NYV4 & T893 & LYNSEESRPYpTNK & 1.59 & 1.93 \\
\hline CDK16 & Cyclin-dependent kinase 16 & Q00536 & S153 & RVpSLSEIGFGK & 1.48 & 1.57 \\
\hline CENPF & Centromere protein $\mathrm{F}$ & P49454 & S1747 & LQLQGLDLpSSR & 0.54 & 1.06 \\
\hline CENPV & Centromere protein $\mathrm{V}$ & Q7Z7K6 & $\begin{array}{l}\text { S47 } \\
\text { S45 }\end{array}$ & $\begin{array}{l}\text { SApSQAGSK } \\
\text { pSASQAGSK }\end{array}$ & $\begin{array}{l}1.93 \\
0.24\end{array}$ & $\begin{array}{l}1.87 \\
0.81\end{array}$ \\
\hline CLASP1 & CLIP-associating protein 1 isoform 5 & Q7Z460-4 & S687 & VVSQpSQPGpSR & 1.79 & 1.64 \\
\hline CLASP2 & CLIP-associating protein 2 & O75122 & S455 & MVSQpSQPGpSR & 2.13 & 1.85 \\
\hline CSNK1D & Casein kinase I isoform $\delta$ & P48730 & S331 & GLPSTApSGR & 0.71 & 0.57 \\
\hline FAM $83 D$ & Protein FAM83D & Q9H4H8 & S462 & GTQpSTEGpSPVSK & 1.78 & 0.99 \\
\hline FANCD2 & Fanconi anemia group D2 protein & Q9BXW9 & S717 & DGGPVTpSQESGQK & 2.20 & 1.25 \\
\hline GINS2 & $\begin{array}{l}\text { DNA replication complex GINS } \\
\text { protein PSF2 }\end{array}$ & Q9Y248 & S182 & TNLQPLESTQpSQDF & 2.42 & 2.07 \\
\hline$G N L 3 L$ & $\begin{array}{l}\text { Guanine nucleotide-binding } \\
\text { protein-like 3-like protein }\end{array}$ & Q9NVN8 & S465 & LLHpSPMTK & 1.70 & 1.20 \\
\hline GSK3B & Glycogen synthase kinase- $3 \beta$ & P49841 & S9 & $\begin{array}{l}\text { TTpSFAESCKPVQQPSA } \\
\text { FGSMK }\end{array}$ & 1.86 & 1.66 \\
\hline$H 2 A F Y$ & $\begin{array}{l}\text { Core histone macro-H2A.1; } \\
\text { Histone } \mathrm{H} 2 \mathrm{~A}\end{array}$ & O75367 & T129 & GKLEAIIpTPPPAK & 0.66 & 0.94 \\
\hline HAUS6 & $\begin{array}{l}\text { HAUS augmin-like complex } \\
\text { subunit } 6\end{array}$ & Q7Z4H7 & S552 & AVLSDpSPQLSEGK & 0.63 & 0.84 \\
\hline HJURP & $\begin{array}{l}\text { Holliday junction recognition } \\
\text { protein }\end{array}$ & Q8NCD3 & S412 & WLIpSPVK & 1.60 & 0.88 \\
\hline$H P 1 B P 3$ & $\begin{array}{l}\text { Heterochromatin protein 1-binding } \\
\text { protein } 3 \text { isoform } 3\end{array}$ & Q5SSJ5-3 & S3 & MApSpSPRPK & 0.47 & 0.89 \\
\hline HP1BP3 & $\begin{array}{l}\text { Heterochromatin protein 1-binding } \\
\text { protein } 3 \text { isoform } 3\end{array}$ & Q5SSJ5-3 & S4 & MApSpSPRPK & 0.47 & 0.89 \\
\hline ID4 & DNA-binding protein inhibitor ID-4 & P47928 & S5 & AVpSPVRPSGR & 1.82 & 1.17 \\
\hline INCENP & Inner centromere protein & Q9NQS7 & $\mathrm{T} 219$ & $\begin{array}{l}\text { TLSPTPASATAPTSQGI } \\
\text { PpTpSDEESTPKK }\end{array}$ & 1.69 & 1.32 \\
\hline INCENP & Inner centromere protein & Q9NQS7 & $\mathrm{T} 292$ & VLAPILPDNFSpTPTGSR & 0.54 & 0.88 \\
\hline ING5 & Inhibitor of growth protein 5 & Q8WYH8 & T147 & RpTSEEDTPK & 0.60 & 0.97 \\
\hline KIF 11 & Kinesin-like protein KIF11 & P52732 & T926 & LDIPTGTpTPQR & 1.68 & 0.98 \\
\hline KIF $1 A$ & Kinesin-like protein KIF1A & Q12756 & S1094 & DVLpSPLRPSR & 1.98 & 0.97 \\
\hline KIF2OA & Kinesin-like protein KIF20A & O95235 & S825 & LQGQVpSAK & 0.64 & 0.98 \\
\hline
\end{tabular}


Table III. Continued.

\begin{tabular}{|c|c|c|c|c|c|c|}
\hline \multirow[b]{2}{*}{ Gene symbol } & \multirow[b]{2}{*}{ Protein } & \multirow[b]{2}{*}{ Uniprot ID } & \multirow[b]{2}{*}{ Phosphosite } & \multirow[b]{2}{*}{ Identified peptides } & \multicolumn{2}{|c|}{ Fold change } \\
\hline & & & & & $3 \mathrm{~h}$ & $24 \mathrm{~h}$ \\
\hline \multirow[t]{2}{*}{ KIF2OB } & \multirow[t]{2}{*}{ Kinesin-like protein KIF20B } & \multirow[t]{2}{*}{ Q96Q89 } & $\mathrm{S} 1740$ & FGDFLQHpSPSILQSK & 1.64 & 0.99 \\
\hline & & & T1644 & HPGCTpTPVTVK & 1.56 & 0.99 \\
\hline \multirow[t]{2}{*}{$L M N B 1$} & \multirow{2}{*}{ Lamin-B1 } & \multirow[t]{2}{*}{ P20700 } & $\mathrm{S} 23$ & AGGPTpTPLpSPTR & 0.46 & 0.82 \\
\hline & & & $\mathrm{T} 20$ & AGGPTpTPLpSPTR & 0.27 & 0.74 \\
\hline \multirow[t]{3}{*}{$L M N B 2$} & \multirow[t]{3}{*}{ Lamin-B2 } & \multirow[t]{3}{*}{ Q03252 } & $\mathrm{S} 17$ & AGGPApTPLpSPTR & 0.51 & 0.77 \\
\hline & & & S404 & ATSSSSGpSLSATGR & 0.63 & 0.88 \\
\hline & & & $\mathrm{T} 14$ & AGGPApTPLpSPTR & 0.51 & 0.77 \\
\hline MAP4 & Microtubule-associated protein 4 & P27816 & S636 & KCpSLPAEEDSVLEK & 0.47 & 1.02 \\
\hline \multirow[t]{3}{*}{ MARCKS } & \multirow{3}{*}{$\begin{array}{l}\text { Myristoylated alanine-rich C-kinase } \\
\text { substrate }\end{array}$} & \multirow[t]{3}{*}{ P29966 } & S145 & AEDGApTPpSPSNETPK & 0.64 & 0.88 \\
\hline & & & S147 & AEDGATPSPpSNETPK & 0.52 & 0.79 \\
\hline & & & $\mathrm{T} 143$ & AEDGApTPpSPSNETPK & 0.55 & 0.93 \\
\hline MCM3 & $\begin{array}{l}\text { DNA replication licensing factor } \\
\text { MCM3 }\end{array}$ & $\mathrm{P} 25205$ & S728 & TADpSQETK & 5.6 & 2.04 \\
\hline MCM6 & $\begin{array}{l}\text { DNA replication licensing factor } \\
\text { MCM6 }\end{array}$ & Q14566 & S762 & EIESEIDpSEEELINK & 9.62 & 2.19 \\
\hline \multirow[t]{2}{*}{$M D C 1$} & \multirow[t]{2}{*}{$\begin{array}{l}\text { Mediator of DNA damage } \\
\text { checkpoint protein } 1\end{array}$} & \multirow[t]{2}{*}{ Q14676 } & S1086 & $\begin{array}{l}\text { QDGpSQEAPEAPLSSE } \\
\text { LEPFHPKPK }\end{array}$ & 2.84 & 2.17 \\
\hline & & & S955 & GEPEGGpSQDQK & 4.36 & 3.35 \\
\hline \multirow[t]{2}{*}{$M E L K$} & \multirow{2}{*}{$\begin{array}{l}\text { Maternal embryonic leucine } \\
\text { zipper kinase }\end{array}$} & \multirow[t]{2}{*}{ Q14680 } & S356 & SNNWpSLEDVTASDK & 1.67 & 1.09 \\
\hline & & & S529 & VFGpSLER & 1.72 & 1.03 \\
\hline MISI8BPI & Mis18-binding protein 1 & C9J2Q8 & S110 & ANYEpSPGK & 1.52 & 1.01 \\
\hline NASP & $\begin{array}{l}\text { Nuclear autoantigenic sperm } \\
\text { protein }\end{array}$ & P49321 & S421 & LVPpSQEETK & 3.08 & 0.49 \\
\hline$N P M 1$ & Nucleophosmin & P06748 & S218 & DSKPSpSpTPR & 0.53 & 0.87 \\
\hline & & & $\mathrm{S} 254$ & MQApSIEK & 0.40 & 0.81 \\
\hline & & & $\mathrm{T} 219$ & DSKPSpSpTPR & 0.54 & 0.88 \\
\hline & & & T199 & SIRDpTPAK & 0.63 & 0.81 \\
\hline NUP214 & $\begin{array}{l}\text { Nuclear pore complex protein } \\
\text { Nup214 }\end{array}$ & P35658 & S678 & ITPPAAKPGpSPQAK & 1.52 & 1.08 \\
\hline ORC2 & $\begin{array}{l}\text { Origin recognition complex } \\
\text { subunit } 2\end{array}$ & Q13416 & $\mathrm{T} 226$ & VVSAPVGKEpTPSKR & 1.67 & 1.04 \\
\hline POLA2 & DNA polymerase $\alpha$ subunit B & Q14181 & $\mathrm{S} 152$ & $\begin{array}{l}\text { pSPHQLLSPSSFpSPSA } \\
\text { TPSQK }\end{array}$ & 1.78 & 1.07 \\
\hline & & & $\mathrm{T} 127$ & AISpTPETPLTK & 1.78 & 1.02 \\
\hline $\begin{array}{l}\text { PTTG1; } \\
\text { PTTG2 }\end{array}$ & Securin; Securin-2 & $\begin{array}{l}\text { O95997; } \\
\text { Q9NZH5 }\end{array}$ & S165; S165 & LFQLGPPpSPVK & 2.06 & 1.02 \\
\hline$R A N B P 2$ & E3 SUMO-protein ligase RanBP2 & P49792 & S955 & FESPATGILpSPR & 1.95 & 1.24 \\
\hline$R B 1$ & Retinoblastoma-associated protein & P06400 & S807 & IPGGNIYIpSPLKpSPYK & 1.66 & 1.08 \\
\hline & & & S811 & IPGGNIYIpSPLKpSPYK & 1.66 & 1.08 \\
\hline & & & $\mathrm{T} 821$ & ISEGLPpTPTKMpTPR & 1.76 & 1.09 \\
\hline & & & $\mathrm{T} 823$ & ISEGLPTPpTKMpTPR & 1.80 & 1.08 \\
\hline & & & T826 & ISEGLPpTPTKMpTPR & 1.77 & 1.09 \\
\hline RBM10 & RNA-binding protein 10 & P98175 & S50 & EYGpSQEGK & 2.55 & 1.52 \\
\hline RECQL5 & ATP-dependent DNA helicase Q5 & O94762 & S815 & $\begin{array}{l}\text { YTGEEDGAGGHpSPAP } \\
\text { PQTEECLR }\end{array}$ & 2.11 & 1.50 \\
\hline REXO4 & RNA exonuclease 4 & Q9GZR2 & S111 & KETpSPQVK & 0.61 & 0.91 \\
\hline$R F C 1$ & $\begin{array}{l}\text { Replication factor } \mathrm{C} \\
\text { subunit } 1\end{array}$ & P35251 & $\mathrm{S} 29$ & TKpSDEETLK & 9.99 & 11.91 \\
\hline SMC1A & $\begin{array}{l}\text { Structural maintenance of } \\
\text { chromosomes protein 1A }\end{array}$ & Q14683 & S957 & $\begin{array}{l}\text { GTMDDISQEEGSpSQG } \\
\text { EDSVSGSQR }\end{array}$ & 2.34 & 1.38 \\
\hline & & & S358 & MEEEpSQpSQGR & 1.81 & 1.16 \\
\hline & & & S360 & MEEEpSQpSQGR & 3.13 & 1.78 \\
\hline
\end{tabular}


Table III. Continued.

\begin{tabular}{|c|c|c|c|c|c|c|}
\hline \multirow[b]{2}{*}{ Gene symbol } & \multirow[b]{2}{*}{ Protein } & \multirow[b]{2}{*}{ Uniprot ID } & \multirow[b]{2}{*}{ Phosphosite } & \multirow[b]{2}{*}{ Identified peptides } & \multicolumn{2}{|c|}{ Fold change } \\
\hline & & & & & $3 \mathrm{~h}$ & $24 \mathrm{~h}$ \\
\hline \multirow[t]{3}{*}{$S M C 3$} & $\begin{array}{l}\text { Structural maintenance of } \\
\text { chromosomes protein } 3\end{array}$ & Q9UQE7 & S1065 & $\begin{array}{l}\text { KGDVEGpSQpSQDEG } \\
\text { EGSGESER }\end{array}$ & 5.91 & 3.47 \\
\hline & & & S1067 & $\begin{array}{l}\text { KGDVEGpSQpSQDEG } \\
\text { EGSGESER }\end{array}$ & 2.14 & 1.63 \\
\hline & & & S1083 & $\begin{array}{l}\text { GSGpSQSSVPSVDQFT } \\
\text { GVGIR }\end{array}$ & 3.22 & 1.69 \\
\hline TOP1 & DNA topoisomerase 1 & P11387 & S97 & VRApSGDAK & 0.58 & 0.81 \\
\hline TOP2A & DNA topoisomerase $2-\alpha$ & P11388 & $\begin{array}{l}\text { S1377 } \\
\text { S1106 }\end{array}$ & $\begin{array}{l}\text { SVVpSDLEADDVK } \\
\text { VPDEEENEEpSDNE } \\
\text { KETEK }\end{array}$ & $\begin{array}{l}2.26 \\
1.62\end{array}$ & $\begin{array}{l}1.17 \\
1.13\end{array}$ \\
\hline TOPBP1 & $\begin{array}{l}\text { DNA topoisomerase 2-binding } \\
\text { protein } 1\end{array}$ & Q92547 & S888 & NAVALSApSPQLK & 2.72 & 1.44 \\
\hline TP53BP1 & $\begin{array}{l}\text { Tumor suppressor p53-binding } \\
\text { protein } 1\end{array}$ & Q12888 & S1068 & GNLLHFPSpSQGEEEKEK & 1.97 & 1.63 \\
\hline TP53BP1 & $\begin{array}{l}\text { Tumor suppressor p53-binding } \\
\text { protein } 1\end{array}$ & Q12888 & S398 & $\begin{array}{l}\text { QDKPMDTSVLpSEEGG } \\
\text { EPFQK }\end{array}$ & 2.06 & 1.35 \\
\hline UIMC1 & $\begin{array}{l}\text { BRCA1-A complex subunit } \\
\text { RAP80 }\end{array}$ & Q96RL1 & $\begin{array}{l}\text { S597 } \\
\text { S101 }\end{array}$ & $\begin{array}{l}\text { ADQGDGPEGpSGR } \\
\text { EVNpSQEEEEEELLR }\end{array}$ & $\begin{array}{l}2.63 \\
1.86\end{array}$ & $\begin{array}{l}1.32 \\
1.33\end{array}$ \\
\hline
\end{tabular}
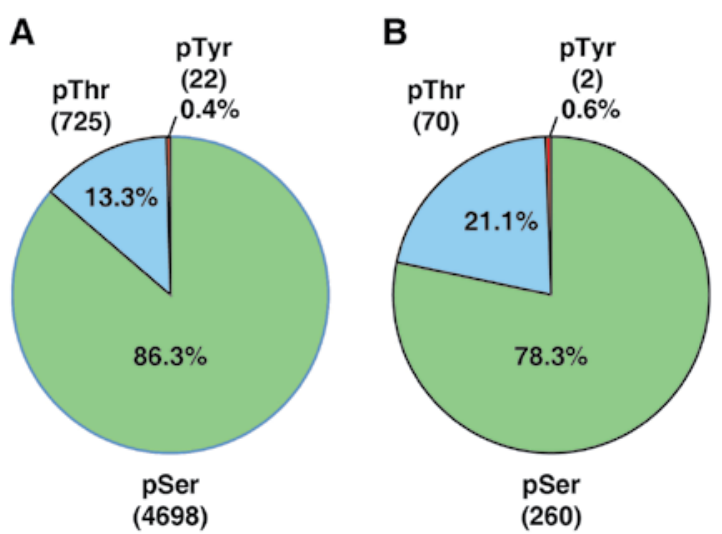

Figure 4. Distribution of identified phosphosites (A) and genistein-regulated phosphosites (B).

processes regulated by genistein in cells, genistein-regulated phosphoproteins identified in our study were analyzed in the DAVID bioinformatics resources $(27,28)$ using the biological process ontology terms. The analysis revealed that proteins involved in the cell cycle, mitosis, DNA replication and cell division were significantly enriched in genistein-regulated phosphoproteins (Table III and data not shown). Although it has been shown that genistein can induce $\mathrm{G} 2 / \mathrm{M}$ cell cycle arrest and decrease the expression of CDK1 in MDA-MB-231 cells after $48 \mathrm{~h}$ of treatment (11), the results here indicated that genistein regulates various phases during the cell cycle. To understand the effects of genistein on regulation of the cell cycle, manual literature curation was performed to find the roles of the phosphorylation of these proteins during the progress of the cell cycle. Fig. 5A shows that three critical CDKs during the progress of the cell cycle were regulated by genistein, while Fig. 5B demonstrates that $3 \mathrm{~h}$ after the treatment, genistein increased the amount of the phosphopeptide 'IGEGpTpYGVVYK', which is shared among CDK1, CDK2, and CDK3. Fig. 5C illustrates that 8 protein critical for DNA replication were regulated by genistein in MDA-MB-231 cells. The quantitative analysis revealed that the phosphorylation levels of these proteins were increased after 3-h treatment with genistein and that the phosphorylation on MCM3, MCM5, and GINS2 even remains higher after 24-h treatment with genistein (Fig. 5D). Fig. 5E shows that genistein decreased phosphorylation level of ESCO2 and increased phosphorylation level of CDC20, PTTG1, SMC1A and SMC3 in cells, suggesting that genistein can inhibit cleavage of the cohesin complex during mitosis. Table III summarized the changes of phosphorylation of the proteins involved in the cell cycle progress. Although the effects of genistein-induced changes of phosphorylation of these proteins cannot be detailed here, for the first time, our data revealed that genistein regulates the cell cycle progression in a more comprehensive manner than previously reported (11).

Genistein activates the DNA damage response pathway in TNBC cells. The enrichment analysis by DAVID revealed that 23 genistein-regulated phosphoproteins are involved in response to DNA damage (data not shown). To understand phosphorylation-based regulation of DNA damage response pathway by genistein, we constructed a DNA damage response pathway by manual literature curation, as shown in Fig. 6A. Here, for the first time, we were able to demonstrate that ATR was hyperphosphorylated at Thr1989, an autophosphorylation site crucial for ATR activation (31), by genistein at $3 \mathrm{~h}$ but not $24 \mathrm{~h}$ (Fig. 6B and $\mathrm{C}$ ), consistent with previous report that genistein metabolite activates ATR in cells (32). In addition, our data also showed 
A

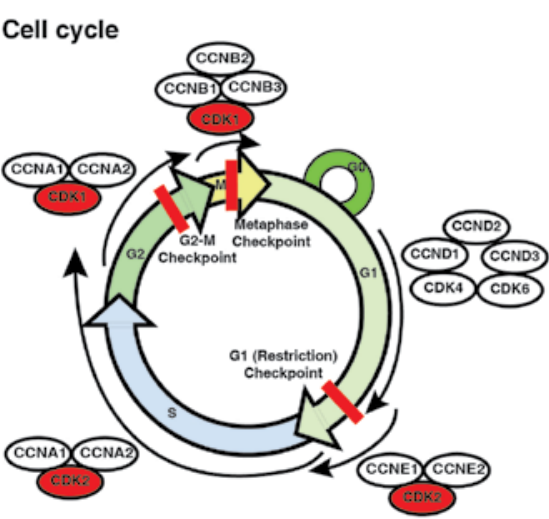

C DNA replication

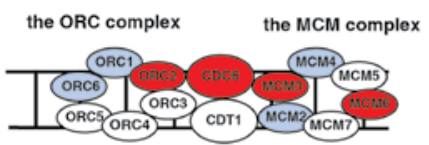

Origin of replication

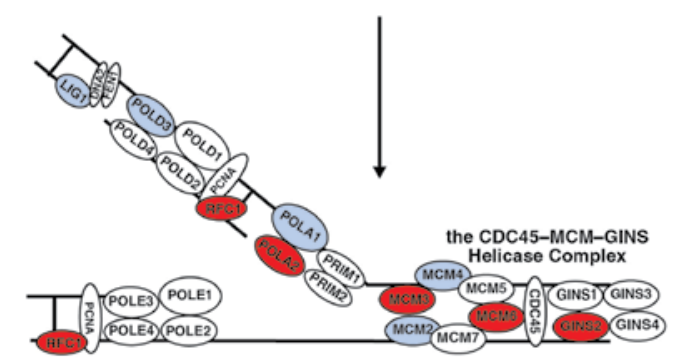

E

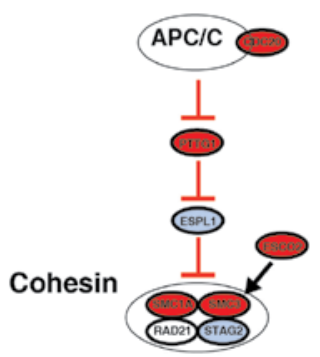

B

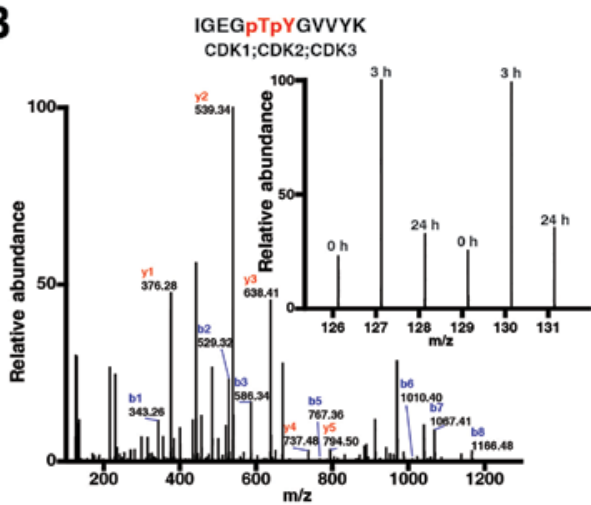

D
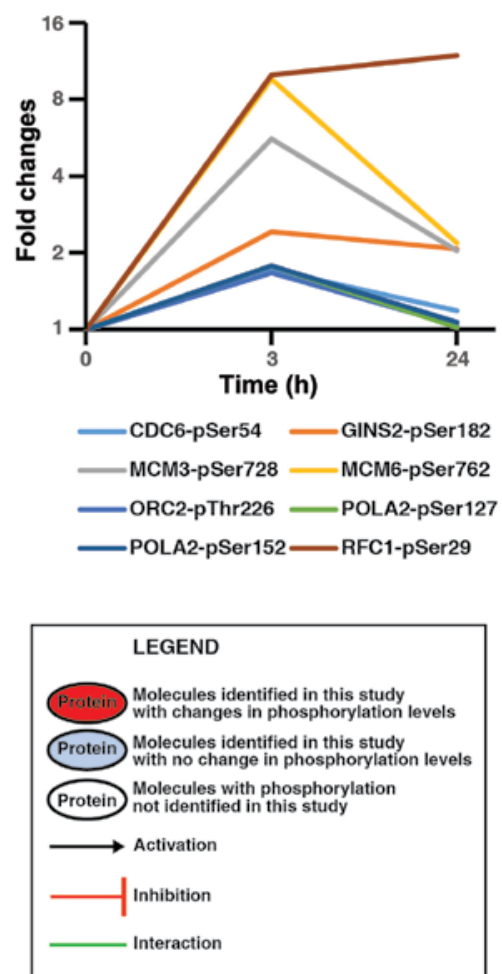

Figure 5. Genistein modulates regulation of the cell cycle. (A) The cell cycle progression regulation by cyclin-CDKs. (B) CDK1 is hyperphosphorylated at Thr14 and Tyr15. The MS/MS spectrum of the phosphopeptide IGEGpTpYGVVYK is annotated (above) and the relative intensities of the TMT reporter ions show the changes of its phosphorylation (bottom). (C) Genistein-regulated phosphoproteins involved in DNA replication. (D) Genistein-induced changes of protein phosphorylation involved in DNA replication. (E) Genistein-regulated phosphoproteins involved in regulation of the cohesin complex. The legends are included in the inset. The expression level of the proteins in the figure remains unchanged or unquantifiable.

that TOPBP1, which activates the ATR-ATRIP complex during stressed DNA replication $(33,34)$, was hyperphosphorylated at Ser888 by genistein at $3 \mathrm{~h}$ but not $24 \mathrm{~h}$ (Fig. 6C). Thus, our data suggest that genistein may induce activation of ATR signaling in MDA-MB-231 cells in an acute manner. Noteworthy, in our analysis, BRCA1 and RAP80 (UIMC1) were hyperphosphorylated by genistein at $3 \mathrm{~h}$, suggesting that genistein may activate the BRCA1-A and -B complexes via the ATR signaling pathway. Fig. 6C illustrates genistein-induced changes of 23 signaling molecules, which were quantitated by TMT-based quantitative phosphoproteomics, in ATM/ATR-mediated DNA damage response. Taken together, our analysis revealed the complexity of genistein-induced DNA damage response, which is more than reported previously by Vauzour and colleagues, especially during the acute treatment phase (32).

\section{Discussion}

Triple-negative breast cancer accounts for approximately $12-17 \%$ of breast cancer cases in women. Patients with triplenegative tumors have relatively poor clinical outlook, evidenced by lower 5 -year survival rate and higher distant recurrence rate than other breast cancer patients. These patients cannot be treated with endocrine therapy or therapy targeting overexpressed receptors, due to no or less expression of ER/HER2/ PR compared with other subtypes of breast cancer $(35,36)$. There is an urgent need to develop a novel therapeutic strategy for these patients. Genistein, one of the major isoflavones in soy products, has been reported to inhibit proliferation of TNBC cells $(8,11,12,29,37,38)$. A number of epidemiological studies reported a significant inverse association between soy 
A

DNA damage response pathway

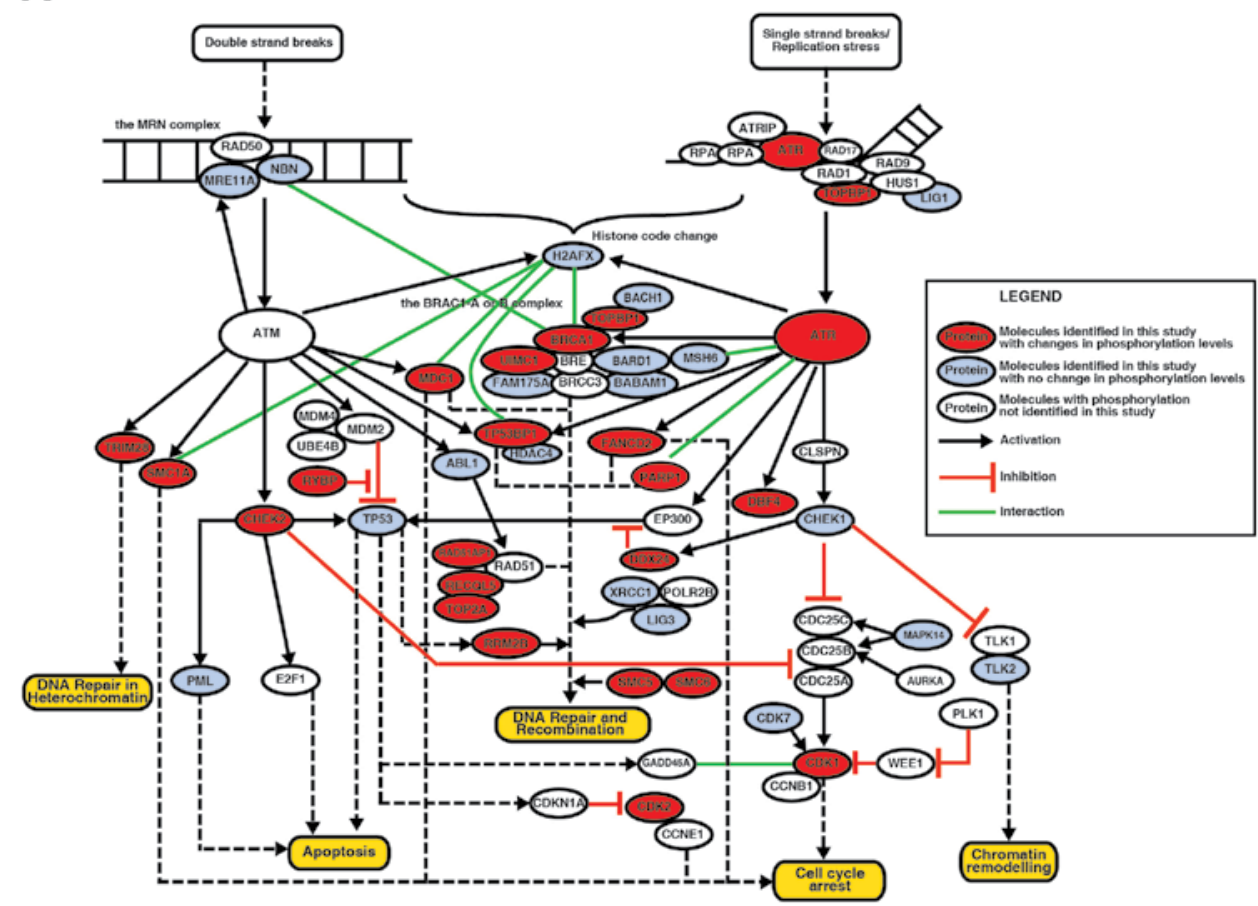

B

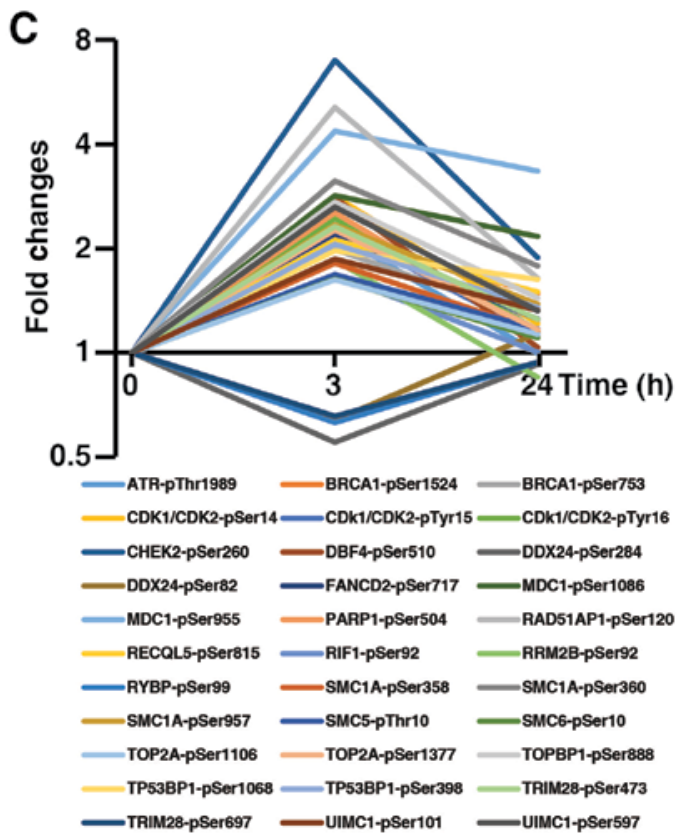

Figure 6. Genistein modulates the DNA damage response pathway. (A) Phosphoproteins regulated by genistein are involved in the DNA damage response pathway. The phosphoproteins identified in our study were annotated in the DNA damage response pathway constructed through manual literature curation. The legends are included in the inset. (B) ATR is hyperphosphorylated at Thr1989. The MS/MS spectrum of the phosphopeptide GVELCFPENEpTPPEGK is annotated (above) and the relative intensities of the TMT reporter ions show the changes of its phosphorylation (bottom). (C) Genistein-induced changes of protein phosphorylation involved in the DNA damage response pathway. The expression level of the proteins in the figure remains unchanged or unquantifiable.

intake and risk of breast cancer incidence and recurrence $(4,5)$. Thus, genistein can serve as a potential attractive therapeutic agent for TNBC.

Previously, a number of groups have attempted to understand the anti-proliferative effects of genistein in TNBC cells, especially MDA-MB-231 cells $(8,10-13,29)$. Genistein may inhibit cell growth and induce apoptosis via multiple signaling pathways. Genistein can upregulate the expression of Bax and p21WAF1 and downregulate the expression of Bcl-2 and p53 (8). It can inhibit NF- $\kappa \mathrm{B}$ activity via the Akt signaling pathway (13) or the Notch-1 pathway (29) or the MEK5/ERK5 pathway (12). Genistein also induces phosphorylation of ERK1/2 (11). However, we did not detect the reported changes of signaling molecules involved in these signaling pathways at a protein level. Especially, our analysis did not detect significant changes in the proteome induced by genistein in MDA-MB231 cells, out of 2087 proteins, only the expression levels of 8 proteins were shown to be changed by genistein (Table II). 
In contrast, for the first time, our data focusing on the acute genistein treatment phase showed that phosphorylation of a number of signaling molecules involved in the regulation of the cell cycle were regulated by genistein in TNBC cells.

In eukaryotes, the cell cycle can be divided into the five different phases: G0, G1, S, G2, and M phases (Fig. 5A). Two classes of proteins, cyclins and cyclin-dependent kinases (CDKs) determine the progress of the cell cycle. Among them, CDK1 and CDK2 are two critical kinases controlling the correct transition of the different phases in the cell cycle (Fig. 5A). Phosphorylation on the Thr14 and Tyr15 sites inhibits CDK1 kinase activity, preventing the G2/M transition (39). Genistein can induce $\mathrm{G} 2 / \mathrm{M}$ phase arrest in MDA-MB-231 cells (9). Here, for the first time, we were able to detect the increased phosphorylation at the Thr14 and Tyr15 sites on CDK1 in MDA-MB-231 cells after $3 \mathrm{~h}$ exposure to genistein, although we cannot exclude the possibility that genistein could increase the conserved Thr14 and Tyr15 sites on CDK2 and CDK3 (Fig. 5B). The data suggest that genistein executes its effects on regulation of the cell cycle in a more acute and direct manner than what previously described (11).

Mitosis and cytokinesis occur during the $\mathrm{M}$ phase of the cell cycle. Our data demonstrated that genistein regulates phosphorylation of a number of proteins involved in mitosis and cytokinesis (Table III). The cohesin complex, consisting of SMC1A, SMC3, RAD21, and STAG2, can form a large protein ring to hold sister chromatids together before anaphase during mitosis (40). When anaphase starts, the anaphase promoting complex (APC) marks an inhibitory protein securin (PTTG1) with ubiquitination for degradation. The destruction of securin allows the activation of a protease called separase (ESPL1), which cleave the cohesin complex to allow the separation of sister chromatids. Phosphorylation of CDC20 by Bubl mediates inhibition of APC by spindle checkpoint (41). ESCO2 is a cohesin acetyltransferase and required for the establishment of sister chromatid cohesin $(42,43)$. As shown in Fig. 5E, our data indicated that genistein decreased phosphorylation level of ESCO2 and increased phosphorylation level of CDC20, PTTG1, SMC1A and SMC3 in cells, suggesting that genistein can inhibit cleavage of the cohesin complex during mitosis.

The kinetochore is the protein complex assembled at each centromere on sister chromatids that serves as the attachment site for spindle microtubules to pull sister chromatids apart during mitosis. CLASP1 and CLASP2 belong to a family of microtubule-associated proteins and are required at kinetochore for attached microtubules $(44,45)$. Our data showed that phosphorylation at the Ser687 site on CLASP1 and at the Ser455 site on CLASP2 were elevated by genistein at 3-h and 24-h time point. CENPF is assembled onto kinetochores at late G2 phase and is involved in chromosome segregation during mitosis (46). Phosphorylation at the Ser1747 site on CENPF was found to be decreased by genistein at 3-h time point and to return to the normal at 24-h point. CENPV was identified from mitotic chromosome scaffolds by mass spectrometry and has been shown to be required for centromere organization, chromosome alignment and cytokinesis (47). Of note, genistein was found to increase phosphorylation at the Ser47 site on CENPV at 3-h and 24-h time points and to decrease phosphorylation at the Ser45 site on CENPV at 3-h, but not 24-h time point. The human Augmin complex (HAUS) plays a critical role in microtubule attachment to the kinetochore and central spindle formation (48). HAUS6, a subunit of the HAUS complex, was found to be hypophosphorylated by genistein at Ser552 at 3-h, but not 24-h time point. MIS18BP1, also called KNL-2, is required for CENP-A incorporation into chromatin. MIS18BP1 and CENP-A localize to centromeres throughout the cell cycle. The depletion of MIS18BP1 in cells causes defect of the kinetochore assembly and chromosome segregation (49). At 3-h time point, phosphorylation of MIS18BP1 at the Ser110 was elevated by genistein, but then decreased to the normal at 24-h. HJURP, a CENP-A chaperon, is also required for CENP-A localization to centromeres and incorporation of newly synthesized CENP-A into centromeres (50). It is sufficient to form a functional de novo kinetochore (51). Phosphorylation of HJURP was observed to be elevated by genistein at 3-h time point. Spindly (SPDL1), a mitotic checkpoint protein, is required for localization of dynein and dynactin to the mitotic kinetochore (52). Farnesylation plays a role in targeting Spindly to kinetochores. Here we reported the elevated phosphorylation of Spindly at Ser555 by genistein at 3-h time point. Our quantitative data on the phosphorylation of these proteins suggest that genistein may regulate the formation of the kinetochore by phosphorylation during mitosis, which has not been reported previously. Taken together, our data suggest that genistein may have a more direct effect on regulation of the cell cycle in a complex manner.

ATM (ataxia-telangiectasia mutated) and ATR (ataxia telangiectasia and Rad3-related protein) are two critical protein kinases to sense DNA lesions induced by DNA damage or DNA replication stress and then to elicit the cellular responses that include cell cycle arrest, DNA repair and apoptosis (53). Whereas ATM mostly responds to double-strand DNA breaks, ATR is activated by a broad spectrum of DNA damage, including persistent single-stranded DNA during stressed replication fork. Genistein can induce the phosphorylation of ATM/Chk2 in irradiated MDA-MB-231 cells (54). Our data showed that at $3 \mathrm{~h}$, genistein can activate ATR by hyperphosphorylation at Thr1989, an autophosphorylation site crucial for ATR activation (31). TOPBP1, an interacting protein of DNA topoisomerase II $\beta$, binds to single-stranded DNA and activates the ATR-ATRIP complex during stressed DNA replication $(33,34)$. Noteworthy, our data also showed that at $3 \mathrm{~h}$, genistein can induce hyperphosphorylation of TOPBP1 at Ser888. Thus, our data suggest acute effects of genistein on ATR signaling in MDA-MB-231 cells.

$B R C A 1$ is a human tumor suppressor gene and its mutations lead to an increased risk for breast cancer. The $B R C A 1$ protein product plays critical roles in DNA repair, cell cycle checkpoint control, and maintenance of genomic stability $(55,56)$. BRCA1 executes its functions by forming at least three different protein complexes (57). The BRCA1-A complex, which contains the BRCA1-BARD1 heterodimer, UIMC1, BRCC3, BRE, FAM175A and BABAM1, recognizes and binds K63-linked polyubiquitin chains present on histone $\mathrm{H} 2 \mathrm{~A}$ and $\mathrm{H} 2 \mathrm{AX}$ at DNA damage sites to promote DNA repair (58). The BRCA1-B complex consisting of the BRCA1BARD1 heterodimer, BACH1 and TOPBP1, binds DNA lesions during $\mathrm{S}$ phase at DNA damage sites and is required for progression through $\mathrm{S}$ phase (59). The BRCA1-C complex, 
which also contains BRCA1-BARD1 heterodimer, RBBP8, and the MRN complex (MRE11A/RAD50/NBS1), binds to the double-stranded DNA breaks during S and G2 phase of the cell cycle and is required for DNA damage-induced Chk1 phosphorylation and the G2/M transition checkpoint $(59,60)$. In our analysis, BRCA1 were hyperphosphorylated at Ser753 and Ser1524 by genistein at 3-h. While phosphorylation at Ser1524 is required for ATM-mediated S phase checkpoint and response to double-stranded DNA breaks $(61,62)$, the role of phosphorylation at Ser753 remains unknown. Moreover, BRCA1-A complex subunit RAP80 (UIMC1), and TOPBP1, a component of the BRCA1 B complex, were also hyperphosphorylated by genistein at 3-h. Phosphorylation at Ser101 of RAP80 (UIMC1) is critical to target the BRCA1-A complex to specific ubiquitin structure at DNA damage sites $(63,64)$. Thus, our data suggest that genistein may activate the BRCA1-A and -B complexes via the ATR signaling pathway. Taken together, we concluded that genistein may affect more acutely the active DNA damage response pathway in a complex manner.

The difference of our data from previous reports may be due to the difference of the time points chosen in each of the studies. We aimed to identify the early signaling events (i.e. 3 -h) in cells after the treatment with genistein, while previous reports were focused on the long-term effects of genistein on signaling pathways $(>24 \mathrm{~h}$ ). Our approach allows us to demonstrate that genistein may induce $\mathrm{G} 2 / \mathrm{M}$ cell cycle arrest and apoptosis by regulating the cell cycle and DNA damage response more acutely and directly than indicated by previous reports. Notably, our data also revealed that genistein can induce hyperphosphorylation of components of the MCM complex, which could lead to inhibition of DNA replication (65). Thus, genistein may induce G2/M cell cycle arrest via stressed DNA replication.

While we describe the phosphoprotein changes in the core components in the cell cycle and the DNA damage response signaling pathways, it is important to keep in mind that these protein modifications are not independent of the other components of these pathways. In fact, these core components interact with many other signaling molecules to mediate the biological effects of genistein in cells. Overall, our studies revealed the complexity of the genistein effects on regulation of the cell cycle and opened promising avenues for future investigation into question regarding early effects in TNBC cells following treatment with genistein.

\section{Acknowledgements}

This study was supported by the Fundamental Research Funds for the Cancer Hospital, Chinese Academy of Medical Sciences (Y.F., no. JK2014B10), National Basic Research Program of China (973 Program, Y.J., no. 2015CB553902), the Fundamental Research Funds for the Central Universities (Z.H., no. 33320140103), the National Natural Science Foundation of China (J.W., General Program: 81372829), and Beijing Municipal Natural Science Foundation (J.W., no. 7142140).

\section{References}

1. Torre LA, Bray F, Siegel RL, Ferlay J, Lortet-Tieulent J and Jemal A: Global cancer statistics, 2012. CA Cancer J Clin 65: $87-108,2015$
2. Reis-Filho JS and Pusztai L: Gene expression profiling in breast cancer: Classification, prognostication, and prediction. Lancet 378: 1812-1823, 2011.

3. Perou CM and Børresen-Dale AL: Systems biology and genomics of breast cancer. Cold Spring Harb Perspect Biol 3: a003293, 2011.

4. Adlercreutz CH, Goldin BR, Gorbach SL, Höckerstedt KA, Watanabe S, Hämäläinen EK, Markkanen MH, Mäkelä TH, Wähälä KT and Adlercreutz T: Soybean phytoestrogen intake and cancer risk. J Nutr 125 (Suppl): S757-S770, 1995.

5. Messina MJ, Persky V, Setchell KD and Barnes S: Soy intake and cancer risk: A review of the in vitro and in vivo data. Nutr Cancer 21: 113-131, 1994.

6. Nechuta SJ, Caan BJ, Chen WY, Lu W, Chen Z, Kwan ML, Flatt SW, Zheng Y, Zheng W, Pierce JP, et al: Soy food intake after diagnosis of breast cancer and survival: An in-depth analysis of combined evidence from cohort studies of US and Chinese women. Am J Clin Nutr 96: 123-132, 2012.

7. Fioravanti L, Cappelletti V, Miodini P, Ronchi E, Brivio M and Di Fronzo G: Genistein in the control of breast cancer cell growth: Insights into the mechanism of action in vitro. Cancer Lett 130: 143-152, 1998.

8. Li Y, Upadhyay S, Bhuiyan M and Sarkar FH: Induction of apoptosis in breast cancer cells MDA-MB-231 by genistein. Oncogene 18: 3166-3172, 1999.

9. Cappelletti V, Fioravanti L, Miodini P and Di Fronzo G: Genistein blocks breast cancer cells in the G(2)M phase of the cell cycle. J Cell Biochem 79: 594-600, 2000.

10. Horia E and Watkins BA: Complementary actions of docosahexaenoic acid and genistein on COX-2, PGE2 and invasiveness in MDA-MB-231 breast cancer cells. Carcinogenesis 28: 809-815, 2007.

11. Li Z, Li J, Mo B, Hu C, Liu H, Qi H, Wang X and Xu J: Genistein induces $\mathrm{G} 2 / \mathrm{M}$ cell cycle arrest via stable activation of ERK1/2 pathway in MDA-MB-231 breast cancer cells. Cell Biol Toxicol 24: 401-409, 2008

12. Li Z, Li J, Mo B, Hu C, Liu H, Qi H, Wang X and Xu J: Genistein induces cell apoptosis in MDA-MB-231 breast cancer cells via the mitogen-activated protein kinase pathway. Toxicol In Vitro 22: 1749-1753, 2008.

13. Gong L, Li Y, Nedeljkovic-Kurepa A and Sarkar FH: Inactivation of NF-kappaB by genistein is mediated via Akt signaling pathway in breast cancer cells. Oncogene 22: 4702-4709, 2003.

14. Thompson A, Schäfer J, Kuhn K, Kienle S, Schwarz J, Schmidt G, Neumann T, Johnstone R, Mohammed AK and Hamon C: Tandem mass tags: A novel quantification strategy for comparative analysis of complex protein mixtures by MS/MS Anal Chem 75: 1895-1904, 2003.

15. Ross PL, Huang YN, Marchese JN, Williamson B, Parker K, Hattan S, Khainovski N, Pillai S, Dey S, Daniels S, et al: Multiplexed protein quantitation in Saccharomyces cerevisiae using amine-reactive isobaric tagging reagents. Mol Cell Proteomics 3: 1154-1169, 2004.

16. Nirujogi RS, Wright JD Jr, Manda SS, Zhong J, Na CH, Meyerhoff J, Benton B, Jabbour R, Willis K, Kim MS, et al: Phosphoproteomic analysis reveals compensatory effects in the piriform cortex of VX nerve agent exposed rats. Proteomics 15: 487-499, 2015.

17. Roitinger E, Hofer M, Köcher T, Pichler P, Novatchkova M, Yang J, Schlögelhofer P and Mechtler K: Quantitative phosphoproteomics of the ataxia telangiectasia-mutated (ATM) and ataxia telangiectasia-mutated and rad3-related (ATR) dependent DNA damage response in Arabidopsis thaliana. Mol Cell Proteomics 14: 556-571, 2015.

18. Wiśniewski JR, Zougman A, Nagaraj N and Mann M: Universal sample preparation method for proteome analysis. Nat Methods 6: 359-362, 2009.

19. Larsen MR, Thingholm TE, Jensen ON, Roepstorff $P$ and Jørgensen TJ: Highly selective enrichment of phosphorylated peptides from peptide mixtures using titanium dioxide microcolumns. Mol Cell Proteomics 4: 873-886, 2005.

20. Rappsilber J, Ishihama Y and Mann M: Stop and go extraction tips for matrix-assisted laser desorption/ionization, nanoelectrospray, and LC/MS sample pretreatment in proteomics. Anal Chem 75: 663-670, 2003.

21. Cox J, Neuhauser N, Michalski A, Scheltema RA, Olsen JV and Mann M: Andromeda: A peptide search engine integrated into the MaxQuant environment. J Proteome Res 10: 1794-1805, 2011. 
22. Cox J, Matic I, Hilger M, Nagaraj N, Selbach M, Olsen JV and Mann M: A practical guide to the MaxQuant computational platform for SILAC-based quantitative proteomics. Nat Protoc 4: 698-705, 2009.

23. Cox J and Mann M: MaxQuant enables high peptide identification rates, individualized p.p.b.-range mass accuracies and proteomewide protein quantification. Nat Biotechnol 26: 1367-1372, 2008

24. Vizcaíno JA, Deutsch EW, Wang R, Csordas A, Reisinger F, Ríos D, Dianes JA, Sun Z, Farrah T, Bandeira N, et al: ProteomeXchange provides globally coordinated proteomics data submission and dissemination. Nat Biotechnol 32: 223-226, 2014.

25. Mi H, Muruganujan A and Thomas PD: PANTHER in 2013 Modeling the evolution of gene function, and other gene attributes, in the context of phylogenetic trees. Nucleic Acids Res 41: D377-D386, 2013.

26. Mi H, Muruganujan A, Casagrande JT and Thomas PD: Large-scale gene function analysis with the PANTHER classification system. Nat Protoc 8: 1551-1566, 2013.

27. Huang W, Sherman BT and Lempicki RA: Bioinformatics enrichment tools: Paths toward the comprehensive functional analysis of large gene lists. Nucleic Acids Res 37: 1-13, 2009.

28. Huang W, Sherman BT and Lempicki RA: Systematic and integrative analysis of large gene lists using DAVID bioinformatics resources. Nat Protoc 4: 44-57, 2009.

29. Pan H, Zhou W, He W, Liu X, Ding Q, Ling L, Zha X and Wang S: Genistein inhibits MDA-MB-231 triple-negative breast cancer cell growth by inhibiting NF- $\kappa$ B activity via the Notch-1 pathway. Int J Mol Med 30: 337-343, 2012.

30. Wang Z, Liang S, Lian X, Liu L, Zhao S, Xuan Q, Guo L, Liu H, Yang Y, Dong T, et al: Identification of proteins responsible for adriamycin resistance in breast cancer cells using proteomics analysis. Sci Rep 5: 9301, 2015.

31. Liu S, Shiotani B, Lahiri M, Maréchal A, Tse A, Leung CC, Glover JN, Yang XH and Zou L: ATR autophosphorylation as a molecular switch for checkpoint activation. Mol Cell 43: 192-202, 2011.

32. Vauzour D, Vafeiadou K, Rice-Evans C, Cadenas E and Spencer JP: Inhibition of cellular proliferation by the genistein metabolite $5,7,3^{\prime}, 4^{\prime}$-tetrahydroxyisoflavone is mediated by DNA damage and activation of the ATR signalling pathway. Arch Biochem Biophys 468: 159-166, 2007.

33. Tuul M, Kitao H, Iimori M, Matsuoka K, Kiyonari S, Saeki H, Oki E, Morita M and Maehara Y: Rad9, Rad17, TopBP1 and claspin play essential roles in heat-induced activation of ATR kinase and heat tolerance. PLoS One 8: e55361, 2013.

34. Kumagai A, Lee J, Yoo HY and Dunphy WG: TopBP1 activates the ATR-ATRIP complex. Cell 124: 943-955, 2006.

35. Foulkes WD, Smith IE and Reis-Filho JS: Triple-negative breast cancer N Engl J Med 363: 1938-1948, 2010.

36. Tichy JR, Deal AM, Anders CK, Reeder-Hayes K and Carey LA Race, response to chemotherapy, and outcome within clinical breast cancer subtypes. Breast Cancer Res Treat 150: 667-674, 2015.

37. Rajah TT, Peine KJ, Du N, Serret CA and Drews NR Physiological concentrations of genistein and $17 \beta$-estradio inhibit MDA-MB-231 breast cancer cell growth by increasing BAX/BCL-2 and reducing pERK1/2. Anticancer Res 32: 1181-1191, 2012

38. Santell RC, Kieu N and Helferich WG: Genistein inhibits growth of estrogen-independent human breast cancer cells in culture but not in athymic mice. J Nutr 130: 1665-1669, 2000.

39. Krek W and Nigg EA: Differential phosphorylation of vertebrate p34cdc2 kinase at the G1/S and G2/M transitions of the cell cycle: Identification of major phosphorylation sites. EMBO J 10 305-316, 1991

40. Hagstrom KA and Meyer BJ: Condensin and cohesin: More than chromosome compactor and glue. Nat Rev Genet 4: 520-534, 2003.

41. Tang Z, Shu H, Oncel D, Chen S and Yu H: Phosphorylation of Cdc20 by Bub1 provides a catalytic mechanism for APC/C inhibition by the spindle checkpoint. Mol Cell 16: 387-397, 2004.

42. Whelan G, Kreidl E, Wutz G, Egner A, Peters JM and Eichele G: Cohesin acetyltransferase Esco2 is a cell viability factor and is required for cohesion in pericentric heterochromatin. EMBO J 31: 71-82, 2012.

43. Vega H, Waisfisz Q, Gordillo M, Sakai N, Yanagihara I, Yamada M, van Gosliga D, Kayserili $\mathrm{H}, \mathrm{Xu} \mathrm{C}$, Ozono K, et al: Roberts syndrome is caused by mutations in ESCO2, a human homolog of yeast ECO1 that is essential for the establishment of sister chromatid cohesion. Nat Genet 37: 468-470, 2005.
44. Maiato H, Fairley EA, Rieder CL, Swedlow JR, Sunkel CE and Earnshaw WC: Human CLASP1 is an outer kinetochore component that regulates spindle microtubule dynamics. Cell 113: 891-904, 2003.

45. Maia AR, Garcia Z, Kabeche L, Barisic M, Maffini S, MacedoRibeiro S, Cheeseman IM, Compton DA, Kaverina I and Maiato H: Cdk1 and Plk1 mediate a CLASP2 phospho-switch that stabilizes kinetochore-microtubule attachments. J Cell Biol 199: 285-301, 2012.

46. Liao H, Winkfein RJ, Mack G, Rattner JB and Yen TJ: CENP-F is a protein of the nuclear matrix that assembles onto kinetochores at late G2 and is rapidly degraded after mitosis. J Cell Biol 130: 507-518, 1995.

47. Tadeu AM, Ribeiro S, Johnston J, Goldberg I, Gerloff D and Earnshaw WC: CENP-V is required for centromere organization, chromosome alignment and cytokinesis. EMBO J 27: 2510-2522, 2008.

48. Lawo S, Bashkurov M, Mullin M, Ferreria MG, Kittler R, Habermann B, Tagliaferro A, Poser I, Hutchins JR, Hegemann B, et al: HAUS, the 8-subunit human Augmin complex, regulates centrosome and spindle integrity. Curr Biol 19: 816-826, 2009.

49. Maddox PS, Hyndman F, Monen J, Oegema K and Desai A Functional genomics identifies a Myb domain-containing protein family required for assembly of CENP-A chromatin. J Cell Biol 176: 757-763, 2007

50. Dunleavy EM, Roche D, Tagami H, Lacoste N, Ray-Gallet D, Nakamura Y, Daigo Y, Nakatani Y and Almouzni-Pettinotti G: HJURP is a cell-cycle-dependent maintenance and deposition factor of CENP-A at centromeres. Cell 137: 485-497, 2009

51. Barnhart MC, Kuich PH, Stellfox ME, Ward JA, Bassett EA, Black BE and Foltz DR: HJURP is a CENP-A chromatin assembly factor sufficient to form a functional de novo kinetochore. J Cell Biol 194: 229-243, 2011.

52. Barisic M, Sohm B, Mikolcevic P, Wandke C, Rauch V, Ringer T, Hess M, Bonn G and Geley S: Spindly/CCDC99 is required for efficient chromosome congression and mitotic checkpoint regulation. Mol Biol Cell 21: 1968-1981, 2010.

53. Maréchal A and Zou L: DNA damage sensing by the ATM and ATR kinases. Cold Spring Harb Perspect Biol 5: 5, 2013.

54. Liu X, Sun C, Jin X, Li P, Ye F,Zhao T, Gong L and Li Q: Genistein enhances the radiosensitivity of breast cancer cells via $\mathrm{G}(2) / \mathrm{M}$ cell cycle arrest and apoptosis. Molecules 18: 13200-13217, 2013.

55. Narod SA and Foulkes WD: BRCA1 and BRCA2: 1994 and beyond. Nat Rev Cancer 4: 665-676, 2004.

56. Venkitaraman AR: Cancer susceptibility and the functions of BRCA1 and BRCA2. Cell 108: 171-182, 2002.

57. Wang B: BRCA1 tumor suppressor network: Focusing on its tail. Cell Biosci 2: 6, 2012.

58. Wang B, Hurov K, Hofmann K and Elledge SJ: NBA1, a new player in the Brcal A complex, is required for DNA damage resistance and checkpoint control. Genes Dev 23: 729-739, 2009.

59. Greenberg RA, Sobhian B, Pathania S, Cantor SB, Nakatani Y and Livingston DM: Multifactorial contributions to an acute DNA damage response by BRCA1/BARD1-containing complexes. Genes Dev 20: 34-46, 2006.

60. Yu X and Chen J: DNA damage-induced cell cycle checkpoint control requires CtIP, a phosphorylation-dependent binding partner of BRCA1 C-terminal domains. Mol Cell Biol 24: 9478-9486, 2004.

61. Xu B, O'Donnell AH, Kim ST and Kastan MB: Phosphorylation of serine 1387 in Brcal is specifically required for the Atm-mediated S-phase checkpoint after ionizing irradiation. Cancer Res 62: 4588-4591, 2002.

62. Cortez D, Wang Y, Qin J and Elledge SJ: Requirement of ATM-dependent phosphorylation of brcal in the DNA damage response to double-strand breaks. Science 286: 1162-1166, 1999.

63. Kim H, Chen J and Yu X: Ubiquitin-binding protein RAP80 mediates BRCA1-dependent DNA damage response. Science 316: 1202-1205, 2007.

64. Sobhian B, Shao G, Lilli DR, Culhane AC, Moreau LA, Xia B, Livingston DM and Greenberg RA: RAP80 targets BRCA1 to specific ubiquitin structures at DNA damage sites. Science 316: 1198-1202, 2007.

65. Ilves I, Tamberg $\mathrm{N}$ and Botchan MR: Checkpoint kinase 2 (Chk2) inhibits the activity of the Cdc45/MCM2-7/GINS (CMG) replicative helicase complex. Proc Natl Acad Sci USA 109: 13163-13170, 2012. 